\title{
AN EXAMINATION OF THE BENEFITS OF DYNAMIC TRADING STRATEGIES \\ IN U.K. CLOSED-END FUNDS
}

Devraj Basu and Jonathan Fletcher

Key Words: Mean-variance analysis, dynamic trading strategies, closed-end funds

JEL Classification: G11, G12

This draft: April 2016

The authors are from the University of Strathclyde.

We are grateful to the helpful comments received from Wayne Ferson, seminar participants from the University of Edinburgh and Heriot-Watt University, and two anonymous reviewers.

Address correspondence to Professor J. Fletcher, Department of Accounting and Finance, University of Strathclyde, Stenhouse Wing, 199 Cathedral Street, Glasgow, G4 0QU, United Kingdom, phone: +44 (0) 141548 4963, fax: +44 (0) 141552 3547, email: j.fletcher@strath.ac.uk 


\title{
AN EXAMINATION OF THE BENEFITS OF DYNAMIC TRADING STRATEGIES \\ IN U.K. CLOSED-END FUNDS
}

\begin{abstract}
We examine the after-cost out-of-sample performance of the unconditional meanvariance (UMV) strategy in the presence of conditioning information (Ferson and Siegel(2001)) using portfolios of U.K. equity closed-end funds. We find that the performance of the UMV strategy significantly improves when using lagged information variables with the highest persistence (first-order autocorrelation) levels and reduces turnover. This strategy is able to outperform alternative dynamic trading strategies and performs well across different subperiods. At low levels of trading costs, the UMV strategy is able to deliver significant value added to investors.
\end{abstract}




\section{Introduction}

Recent studies have examined whether investors can exploit predictability in individual U.S. mutual funds (Avramov and Wermers(2006)), hedge funds (Avramov, Kosowski, Naik and Teo(2011)), and European mutual funds (Banegas, Gillen, Timmermann and Wermers(2013)), by focusing on variations in manager skill, factor loadings, and factor risk premiums. These studies use conditional mean-variance strategies and find that such strategies deliver significant superior performance. The use of conditional mean-variance (CMV) strategies does not exploit the optimal use of return predictability, which is to select portfolios on the unconditional mean-variance (UMV) frontier in the presence of conditioning information (Hansen and Richard(1987), Ferson and Siegel(2001)) ${ }^{1}$. Studies by Ferson and Siegel(2009), Abhyankar, Basu and Stremme(2012), and Penaranda(2014) find significant benefits in the optimal use of return predictability using test assets such as size/book-to-market (BM) portfolios ${ }^{2}$.

We examine the benefits of using the UMV strategy in trading strategies in U.K. equity closed-end fund portfolios ${ }^{3}$. We compare the performance of the UMV strategy to the CMV strategy and the alternative approach of Brandt and Santa-Clara(2006) which models the optimal weights as a linear function of lagged information variables (Passive/Managed). We use a wide range of lagged information variables in our study and we evaluate the out-ofsample performance of the strategies between January 1995 and December 2014.

\footnotetext{
${ }^{1}$ Hansen and Richard(1987) show that every UMV strategy is a CMV strategy but the converse is not necessarily true.

${ }^{2}$ Chiang(2015) explores the optimal use of return predictability in mean-variance active tracking error strategies. Ferson and Siegel(2015) examine the benefits of the optimal use of return predictability in optimal orthogonal portfolio strategies.

${ }^{3}$ Closed-end funds are known as investment trusts in the U.K.
} 
One feature of the UMV strategy, in addition to the alternative mean-variance strategies, is that they do require high turnover. Fletcher(2011) finds that the superior performance of the UMV strategy disappears in U.K. stock returns after adjusting for trading costs due to the high turnover. Abhyankar et al(2012) find that the level of persistence (firstorder autocorrelation) in the lagged information variables has an impact on the turnover of the UMV strategy. Lagged information variables with the highest persistence levels (close to 1) lead to the lowest trading costs for the UMV strategy. However the most persistent lagged information variables are most likely to be subject to the spurious regression bias in predictive regressions (Ferson, Sarkissian and Simin(2003)). We examine whether the choice of the lagged information variables has a significant impact on the after-cost performance of the UMV strategy. We compare the performance of the UMV strategy using the most persistent lagged information variables to one which uses lagged information variables with the highest predictability from the predictive regression, and to the UMV strategy which uses all lagged information variables.

Our study makes a number of contributions to the literature. We extend the prior evidence of the optimal use of return predictability in Ferson and Siegel(2009), Fletcher(2011), Abhyankar et al(2012), and Penaranda(2014) among others by evaluating performance after adjusting for trading costs. We provide a fuller examination of whether the choice of lagged information variables has an impact on the after-cost performance of the UMV strategy. Our study uses portfolios of closed-end funds rather than test assets such as size/book-to-market (BM) portfolios. The attraction of using managed funds is that it allows us to consider whether dynamic trading strategies can deliver significant value added to investors even where the funds have neutral performance (Fletcher and Marshall(2014)). By focusing on closed-end funds and the UMV strategy, we extend the prior studies of the performance of dynamic trading strategies in managed funds such as Avramov and 
Wermers(2006), Avramov et al(2011), and Banegas et al(2013) among others by using the UMV strategy and focusing on closed-end funds. Closed-end funds differ from open-end funds since the value added depends not only on performance ability, costs, expenses, but also on the behavior of the fund discount $/$ premium $^{4}$.

There are three main findings in our study. First, we find that the choice of lagged information variables has a significant impact on the after-cost performance of the UMV strategy. Using the three lagged information variables with the highest persistence levels delivers the best performance for the UMV strategy. Second, we find the UMV strategy provides the most consistent performance across the different subperiods. The UMV strategy performs particularly well in recession states and bearish market states. Third, we find at lower levels of trading costs, the UMV strategy delivers significant value added to investors. Our results suggest that there are benefits in the optimal use of return predictability for trading strategies in domestic equity closed-end fund portfolios.

The paper is organized as follows. Section II describes the research method. Section III discusses the data. Section IV reports the empirical results and the final section concludes.

\section{Research Method}

\section{A) Mean-Variance Analysis in the Presence of Conditioning Information}

\footnotetext{
${ }^{4}$ See Dimson and Minio-Paluello(2002) and Cherkes(2012) for reviews of the alternative explanations of the closed-end fund discount. Andriosopoulos, Fletcher and Marshall(2015) provide a review of non-US closed-end funds. Recent studies by Berk and Stanton(2007) and Cherkes, Sagi and Stanton(2009) develop explanations of the fund discount in relation to expectations about future managerial performance ability or to the liquidity benefits provided by the funds. Ramadorai(2012) provides support for rational theories of the discount in explaining the closed hedge fund premium.
} 
Hansen and Richard(1987) derive the theoretical framework of mean-variance analysis in the presence of conditioning information. Using the excess returns of $\mathrm{N}$ risky assets over the risk-free return, portfolios on the CMV frontier solve the following problem:

$$
\operatorname{Min} \mathrm{E}\left(\mathrm{r}_{\mathrm{pt}+1}{ }^{2} \mid \mathrm{Z}_{\mathrm{t}}\right)
$$

subject to $\mathrm{E}\left(\mathrm{r}_{\mathrm{pt}+1} \mid \mathrm{Z}_{\mathrm{t}}\right)=$ Target conditional expected excess return

where $r_{p t+1}$ is the excess return of the optimal portfolio at time $t+1$, and $Z_{t}$ is the information set of investors at time $\mathrm{t}$, which is a $(\mathrm{L}+1,1)$ vector consisting of a constant and $\mathrm{L}$ lagged information variables. The CMV problem in equation (1) assumes that the remainder of the wealth of the investor is invested in the risk-free asset so that the sum of the weights in the $\mathrm{N}$ risky assets and risk-free asset equals 1 .

Using the Hansen and Richard(1987) decomposition of the CMV frontier, the optimal weights of the $\mathrm{N}$ risky assets $\left(\mathrm{x}\left(\mathrm{Z}_{\mathrm{t}}\right)\right)$ are given by:

$$
\mathrm{x}\left(\mathrm{Z}_{\mathrm{t}}\right)=\left[\mathrm{E}\left(\mathrm{r}_{\mathrm{pt}+1} \mid \mathrm{Z}_{\mathrm{t}}\right) / \mathrm{B}_{\mathrm{t}}\right] \Gamma_{\mathrm{t}}^{-1} \mu_{\mathrm{t}}
$$

where $\mathrm{B}_{\mathrm{t}}=\mu_{\mathrm{t}}{ }^{\prime} \Gamma_{\mathrm{t}}^{-1} \mu_{\mathrm{t}}, \Gamma_{\mathrm{t}}$ is the conditional $(\mathrm{N}, \mathrm{N})$ second moment matrix of the excess returns of the $\mathrm{N}$ risky assets at time $\mathrm{t}$, and $\mu_{\mathrm{t}}$ is the $(\mathrm{N}, 1)$ vector of conditional expected excess returns at time t. The conditional second moment matrix is calculated as:

$$
\Gamma_{\mathrm{t}}=\Sigma_{\mathrm{t}}+\mu_{\mathrm{t}} \mu_{\mathrm{t}}
$$

where $\Sigma_{\mathrm{t}}$ is the $(\mathrm{N}, \mathrm{N})$ conditional covariance matrix at time t.

Hansen and Richard(1987) also derive the UMV frontier in the presence of conditioning information ${ }^{5}$. The goal of the investor is to select an optimal strategy each period $\left(\mathrm{x}\left(\mathrm{Z}_{\mathrm{t}}\right)\right)$ to minimize $\mathrm{E}\left(\mathrm{r}_{\mathrm{pt}+1^{2}}{ }^{2}\right)$ subject to a target unconditional expected excess return. Ferson and Siegel(2001) derive the closed-form solutions for UMV portfolios. Using the

\footnotetext{
${ }^{5}$ Penaranda and Sentana(2015) explore the duality between portfolio and stochastic discount factor unconditional mean-variance frontiers in the presence of conditioning information and the implications that this has for empirical research.
} 
Hansen and Richard decomposition, the optimal weights, when using excess returns, can be written as:

$$
\mathrm{x}\left(\mathrm{Z}_{\mathrm{t}}\right)=\left[\mathrm{E}\left(\mathrm{r}_{\mathrm{p}}\right) / \mathrm{E}\left(\mathrm{B}_{\mathrm{t}}\right)\right] \Gamma_{\mathrm{t}}^{-1} \mu_{\mathrm{t}}
$$

where $E\left(B_{t}\right)$ is the unconditional expected value of $B_{t}$ and $E\left(r_{p}\right)$ is the target unconditional expected excess return ${ }^{6}$.

The difference in optimal weights of the UMV and CMV strategies is that the scaling of $\Gamma_{\mathrm{t}}^{-1} \mu_{\mathrm{t}}$ in equation (4) is constant but the scaling of $\Gamma_{\mathrm{t}}^{-1} \mu_{\mathrm{t}}$ in equation (2) is time varying. If the target conditional expected excess return each period is set equal to target unconditional expected excess return, then the only difference between the strategies is that for the CMV strategy $B_{t}$ can change every period whereas for the UMV strategy $E\left(B_{t}\right)$ is constant. Ferson and Siegel(2001) show that the UMV strategy is more conservative in response to extreme signals of high conditional expected returns due to the unconditional mean-variance objective of the investor (see also Abhyankar et al(2012)).

The solutions to the UMV and CMV strategies require the modelling of conditional moments. An alternative approach to including conditioning information into mean-variance analysis that avoids the specification of conditional moments is used by Brandt and SantaClara(2006) (Passive/Managed) ${ }^{7}$. Brandt and Santa-Clara assume that the optimal weights at time $t$ are a linear function of $Z_{t}$ given by:

$$
x\left(Z_{t}\right)=\theta Z_{t}
$$

\footnotetext{
${ }^{6}$ Penaranda(2014) define a new class of efficient returns that use conditioning information known as Performance Efficient (PE) returns. When using excess returns, the optimal weights in the PE strategy are the same as the UMV strategy. It is only when working with gross returns and the gross risk-free return is time varying do the two strategies result in different weights.

${ }^{7}$ See also Bansal, Dahlquist and Harvey(2004).
} 
where $\theta$ is a $(\mathrm{N}, \mathrm{L}+1)$ matrix of coefficients in the portfolio weight function. The portfolio weight function can be estimated by:

$$
\theta=\left[\mathrm{E}\left(\mathrm{r}_{\mathrm{p}}\right) / \mathrm{B}\right] \Gamma^{-1} \mu
$$

where $\mu$ is a $(\mathrm{N}(\mathrm{L}+1), 1)$ vector of expected excess returns of the $\mathrm{N}$ risky assets and NL scaled lagged excess returns (L lagged information variables multiplied by the corresponding $\mathrm{N}$ excess returns (Cochrane(2005)), $\Gamma$ is the $(\mathrm{N}(\mathrm{L}+1), \mathrm{N}(\mathrm{L}+1))$ matrix of the second moments of the $\mathrm{N}$ excess returns and scaled excess returns, and $\mathrm{B}=\mu^{\prime} \Gamma^{-1} \mu$. The Passive/Managed approach seeks to approximate the UMV frontier by expanding the investment universe to include not only the $\mathrm{N}$ excess returns but also the scaled excess returns, where the investor then holds a passive combination in the augmented investment universe.

\section{B) Evaluating the Performance of the Mean-Variance Strategies}

We evaluate the out-of-sample performance of the UMV, CMV, and Passive/Managed strategies ${ }^{8}$ using the following approach. At the start of each month between January 1995 and December 2014, we estimate the relevant inputs for the strategies using a rolling estimation window of 60 months. We set the target unconditional and conditional expected excess returns equal to $0.5 \%$. We set the targest expected excess return at $0.5 \%$ since Kirby and Ostdiek(2012) suggest specifying a lower expected excess return to ensure a fairer comparison with the $1 / \mathrm{N}$ strategy (which we use as a benchmark strategy) rather than using the tangency portfolio. For the CMV and UMV strategies, we estimate the relevant inputs $\mu_{\mathrm{t}}$ and $\Gamma_{\mathrm{t}}$ using a given model of the conditional moments. The estimate of $\Gamma_{\mathrm{t}}$ is calculated as in equation (3) using the estimates of $\mu_{\mathrm{t}}$ and $\Sigma_{\mathrm{t}}$.

Our main model of conditional moments follows Ferson and Siegel(2009) and Abhyankar et al(2012) and uses the fitted values of the predictive regression of the $\mathrm{N}$ excess

\footnotetext{
${ }^{8} \mathrm{We}$ focus on these strategies as these strategies are the main methods of incorporating conditioning information into mean-variance dynamic trading strategies.
} 
returns on a constant and the $\mathrm{L}$ lagged information variables to estimate $\mu_{\mathrm{t}}$. The coefficients from the predictive regression are estimated from the estimation window. The $\mu_{\mathrm{t}}$ is calculated at the start of the month using the estimated coefficients from the predictive regression and the $Z_{t}$ available at the start of the month. We assume the conditional covariance matrix is constant and compute as the Maximum Likelihood (ML) estimate of the residual covariance matrix from the predictive regressions during the estimation window. Given the estimates of $\mu_{t}$ and $\Gamma_{t}$, we then calculate $B_{t}$ and the corresponding optimal weights of the CMV strategy from equation (2). For the UMV strategy, we calculate $E\left(B_{t}\right)$ as the average value of $\mathrm{B}_{\mathrm{t}}$ during the estimation window, and calculate the optimal weights of the UMV strategy from equation $(4)^{9}$.

For the Passive/Managed strategy, we estimate $\theta$ using the sample moments of $\mu$ and $\Gamma$ for the augmented investment universe of the $\mathrm{N}$ excess returns and NL scaled excess returns over the estimation window. We then multiply $\theta$ by $Z_{t}$ to get the optimal weights of the Passive/Managed strategy as in equation (5). Using the optimal weights of the three mean-variance strategies, we calculate the monthly portfolio excess returns. This approach generates a time-series of out-of-sample portfolio excess returns.

We compare the performance of the UMV, CMV, and Passive/Managed strategies to two alternative benchmarks. The first is the $1 / \mathrm{N}$ strategy which invests an equal amount in each asset each period. DeMiguel, Garlappi and Uppal(2009) find that the $1 / \mathrm{N}$ strategy performs well relative to alternative mean-variance strategies. The second benchmark is the passive mean-variance (PMV) strategy. This strategy is calculated as in equation (6) using the sample moments of the $\mathrm{N}$ excess returns during the estimation window.

\footnotetext{
${ }^{9}$ There are lots of different ways we could model the conditional moments which would change the UMV and CMV strategies. We examine later in the paper, the impact of using a time varying conditional covariance matrix.
} 
We evaluate the out-of-sample performance of the $1 / \mathrm{N}$ and mean-variance strategies using a number of performance measures. The first measure we use is the Sharpe(1966) performance measure and is given by the average portfolio excess return divided by the standard deviation of portfolio excess returns. The second measure we use is the Certainty Equivalent Return (CER) performance and is given by:

$$
\mathrm{CER}=\mathrm{r}_{\mathrm{p}}-(\gamma / 2) \sigma_{\mathrm{p}}^{2}
$$

where $r_{p}$ is the average excess return of strategy $p, \sigma_{p}^{2}$ is the variance of the excess returns of strategy $\mathrm{p}$, and $\gamma$ is the assumed level of risk aversion. We compute the CER performance for each strategy for $\gamma=5$. The third measure we use is the Jensen(1968) measure relative to the four-factor Carhart(1997) model ${ }^{10}$. The Jensen measure is given by the intercept of the regression of the excess returns of the optimal portfolio strategy on a constant and the four factors in the Carhart model.

The final performance measure we use is the performance fee $\left(\Delta_{\gamma}\right)$ of Kirby and Ostdiek(2012) (see also Fleming, Kirby and Ostdiek(2001,2003)). The performance fee is the fee (as a fraction of invested wealth) that makes the expected utilities of two alternative strategies equal to one another. The performance fee assumes that investors have quadratic utility functions. Define strategy $\mathrm{i}$ as the $1 / \mathrm{N}$ strategy and strategy $\mathrm{j}$ as one of the optimal asset allocation strategies. Kirby and Ostdiek interpret the performance fee as the maximum fee that an investor would be willing to pay each period to change from strategy i to strategy j. The performance fee can be calculated as:

$$
\Delta_{\gamma}=-\gamma^{-1}\left[1-\gamma\left(E\left(R_{p j t+1}\right)\right]+\gamma^{-1}\left[\left(\left(1-\gamma E\left(R_{p j t+1}\right)\right)^{2}-2 \gamma E\left(U\left(R_{p i t+1}\right)-U\left(R_{p j t+1}\right)\right)\right]^{1 / 2}\right.\right.
$$

where $\gamma$ is the relative risk aversion level, $E\left(R_{\mathrm{pjt}}\right)$ is the expected portfolio return of strategy $j$, and $E\left[U\left(R_{p i t+1}\right)-U\left(R_{p j t+1}\right)\right]$ is the expected difference in utility for a quadratic utility investor

\footnotetext{
${ }^{10}$ Details on the formation of the factors in the Carhart(1997) model are included in the Appendix.
} 
between the $1 / \mathrm{N}$ strategy (strategy i) and strategy $\mathrm{j}$. We compute the performance fee for $\gamma=$ 5 for each mean-variance strategy.

We also estimate the turnover of each strategy as in Kirby and Ostdiek(2012). Turnover is defined as the fraction of invested wealth traded each period. We estimate the turnover each month as:

$$
\text { Turnover }_{\mathrm{p}}=\sum_{\mathrm{i}=1} \mathrm{~N}\left|\mathrm{X}_{\text {pit }}-\mathrm{X}_{\text {pit-1 }}\right|+\left|\sum_{\mathrm{i}=1} \mathrm{~N}^{\mathrm{X}}\left(\mathrm{X}_{\text {pit }}-\mathrm{X}_{\text {pit-1 }}\right)\right|
$$

where $\mathrm{x}_{\mathrm{pit}}$ is the optimal weight of asset $\mathrm{i}$ at the start of month $\mathrm{t}$ for strategy $\mathrm{p}, \mathrm{x}_{\mathrm{pit}-1}$ is the optimal weight of asset $\mathrm{i}$ in strategy $\mathrm{p}$ at the start of month $\mathrm{t}-1$ adjusted for buy and hold returns at time t. The turnover measure reflects the fact that the portfolio weights change even without any explicit trading due to the return performance of the assets in the portfolio. We calculate the time-series average turnover for each strategy.

Our focus in this study is to evaluate the performance of the different strategies after controlling for the impact of turnover and trading costs. We estimate the after-cost performance of the strategies by adjusting the portfolio excess returns for the impact of turnover and trading costs. We initially assume a level of proportional cost per transaction of 50 basis points as in DeMiguel et al(2009) and Kirby and Ostdiek(2012) but also consider lower trading costs of 10 basis points as in DeMiguel, Nogales and Uppal(2014). We use the $z$-test of Ledoit and Wolf(2008) ${ }^{11}$ to examine whether the after-cost Sharpe measures for every pair of strategies are equal to each other. We also adapt the $z$-test of Ledoit and Wolf(2008)) to examine whether the after-cost CER measures are equal to one another for every pair of strategies.

\footnotetext{
${ }^{11}$ Ledoit and Wolf(2008) derive the $z$-test using the delta method. The parameters to calculate the Sharpe measure can be estimated as moment conditions in a generalized method of moments (GMM) (Hansen(1982)) estimation. The delta method is then used to derive the $z$-test that the Sharpe performance measures of two strategies are equal to one another.
} 
We use a one-tail $z$-test to examine the null hypothesis that $\Delta_{\gamma} \leq 0$ similar to Kirby and Ostdiek(2012). If there are significant performance benefits after trading costs in the optimal use of return predictability via the UMV strategy, we expect the UMV strategy to provide significant higher after-cost Sharpe and CER performance than all the other strategies and deliver significant positive performance fees. If the UMV strategy delivers significant value added to investors, we expect to find significant positive Jensen performance.

\section{Data}

\section{A) Investment Universe}

We examine the performance of the UMV, CMV, and Passive/Managed strategies using an investment universe of the excess returns of four closed-end fund portfolios sorted by U.K. equity objectives and the one-month U.K. Treasury Bill return. The sample period covers January 1990 and December 2014. All of the data is collected from the London Share Price Database (LSPD) unless otherwise specified. We collect the Treasury Bill return from LSPD and Datastream. We form our closed-end fund sample by identifying each year between 1990 and 2014, all closed-end funds with an U.K. equity objective. We include funds within the U.K. All Companies, U.K. Equity Income, U.K. Smaller Companies, and U.K. Equity and Bond Income.

The investment sector information for each fund is collected each year ${ }^{12}$ from Money Management, the Association of Investment Companies (AIC) web site, and the Investment Trusts magazine. We track the history of each fund throughout the sample period using the

${ }^{12}$ The investment sectors have changed names over the years. The four sectors are the current names of the U.K. investment sectors as at the end of the sample period. In the early part of the sample period, there was a U.K. General sector. We allocate trusts in the U.K. General sector to the U.K. All Companies sector since most trusts transferred to this sector when the classifications changed. 
data from LSPD. If a fund changes to a split capital fund or secondary share, we exclude the fund from that point in the sample. Where a fund changes to an international equity sector or a specialist sector, we exclude the fund from that point in the sample. There are 228 closedend funds in our sample.

For each fund, we collect the stock returns of the funds from LSPD so as to focus on the value added of the funds (Aragon and Ferson(2008)). We form a value weighted of funds for each of the four investment sectors as follows. At the start of each year, all funds are ranked on the basis of their investment sector and allocated to one of four portfolios. We then calculate the value weighted buy and hold return for each month during the year using the market value weights of the funds from LSPD at the start of the year for the initial weights. Where a fund has missing return data during the year due to death, temporary suspension, changes to a split capital fund, or any other reason, we code the missing returns to zero as in Liu and Strong(2008). To be included in the closed-end fund portfolios for a given year, we only require that funds have a U.K. equity sector and a non-zero market value. Our approach to forming the closed-end fund portfolios minimizes the impact of survivorship and look-ahead bias (Brown, Goetzmann, Ibbotson and Ross(1992), Carhart, Carpenter, Lynch and Musto(2002)) as we include funds with only a small number of return observations in the closed-end fund portfolios.

\section{B) Information Variables}

We use nine information variables to proxy for the information set of investors. The choice of these information variables is motivated by prior studies such as Fama and French(1988,1989), Ferson and Siegel(2009), Cooper and Priestley(2009), Abhyankar et al(2012), Rapach, Strauss and Zhou(2012), Bakshi, Panayotov and Skoulakis(2014) among 
others $^{13}$. We use the lagged annualized dividend yield (DY) on the market index, the lagged return on the one-month Treasury Bill $\left(\mathrm{R}_{\mathrm{f}}\right)$, the lagged term spread (Term), the lagged default spread (Default), the two month lag in the monthly change in the Retail Price Index (Inflation), the two month lag in the output gap, the lagged excess U.K. market returns (Market), the lagged quarterly log growth in the Baltic Dry Index (BDI), and the lagged excess (\$) return of the U.S. market index. Details on the formation of the lagged information variables are included in the Appendix.

Table 1 reports summary statistics of the four U.K. equity closed-end fund portfolios (panel A) and nine lagged information variables (panel B) between January 1990 and December 2014. The summary statistics of the closed-end fund portfolios in panel A of the table are the mean, standard deviation, minimum, and maximum monthly excess returns (\%). The summary statistics of the lagged information variables in panel B include the mean, standard deviation, and first-order autocorrelation $\left(\rho_{1}\right)$.

To examine the predictive ability of the lagged information variables, we estimate predictive regressions of the closed-end fund portfolio excess returns on a constant and each lagged information variable separately. The second last column of Table 1 includes the maximal $\mathrm{R}^{2}$ of Lo and MacKinlay(1997), which is the combination of the four closed-end fund portfolios which has the maximum predictability by the lagged information variable. The final column $(\Omega)$ of the table reports the difference between the average ex ante conditional squared Sharpe(1966) performance from the optimal use of predictability (Proposition 2 of Abhyankar et al(2012)) and the squared Sharpe performance of the optimal fixed weight portfolio strategy in the test assets. The difference captures the hypothetical benefits of the optimal use of predictability for a given lagged information variable.

\footnotetext{
${ }^{13}$ Lettau and Ludvigson(2010) and Rapach and Zhou(2013) provide excellent recent reviews of time-series predictability in stock returns.
} 
Proposition 3 of Abhyankar et al shows that under the assumptions of the linear predictive regressions with a constant conditional covariance matrix, the null hypothesis that $\Omega=0$ can be tested by a Wald test (T $\Omega$ ) which has an asymptotic $\chi^{2}$ distribution with $\mathrm{N}$ degrees of freedom or a $F$ test given by $((\mathrm{T}-\mathrm{N}-1) / \mathrm{N}) \Omega$ which has a $F$ distribution with $\mathrm{N}$ and $\mathrm{T}-\mathrm{N}-1$ degrees of freedom in finite samples. Table 1 uses $p$ values based on the Wald test. To conserve space, the table does not report the slope coefficients, $t$-statistics, and $\mathrm{R}^{2}$ from the predictive regressions but these are available on request.

Table 1 here

Panel A of Table 1 shows that there is a reasonable spread in the average excess returns of the four closed-end fund portfolios. The average excess returns range between 0.008\% (Equity and Bond Income) and 0.479\% (Small Companies). The Equity Income portfolio has the lowest volatility across the four closed-end fund portfolios and the Small Companies portfolio has the highest volatility.

Panel B of Table 1 shows that the BDI lagged information variable has the highest volatility across the nine lagged information variables. The magnitude of the volatility is similar to Bakshi et al(2014). Bakshi et al report that the volatility is even higher if the log monthly growth in the BDI index is used. There is a wide range in the autocorrelations across the lagged information variables. The DY, $\mathrm{R}_{\mathrm{f}}$, Term, and Output Gap lagged information variables have the most persistent time-series where the first-order autocorrelation exceeds 0.93. In contrast, the Default, Inflation, Market, and US Market lagged information variables have the least persistent time-series with a first-order autocorrelation below 0.22 . The correlations between the lagged information variables are in general close to 0 . There are four correlations above 0.4 in absolute terms, which includes 
DY and $R_{f}$ at $0.448, R_{f}$ and Term at -0.756 , Default and Market at 0.422 , and Market and US Market at 0.780 .

In unreported tests, all of the lagged information variables have at least one significant slope coefficient in the predictive regressions at the $10 \%$ significance level. The signs of the slope coefficients are consistent with prior research. All of the closed-end fund portfolios have at least four significant slope coefficients at the 10\% level. Excluding the Market and US Market lagged information variables, all of the individual $\mathrm{R}^{2} \mathrm{~S}$ are below $4.1 \%$ and so the degree of predictability is small in statistical terms ${ }^{14}$.

The final column of Table 1 shows that there are significant hypothetical benefits of the optimal use of predictability for a number of the lagged information variables. The null hypothesis of $\Omega=0$ can be rejected at the $10 \%$ level for six of the lagged information variables. The benefits of the optimal use of return predictability are largest for the Market, and US Market lagged information variables and smaller for the DY, $\mathrm{R}_{\mathrm{f}}$, Term, and Default lagged information variables. These results are similar to Abhyankar et al(2012) in U.S. stock returns.

\section{Empirical Results}

We begin our empirical analysis by examining the out-of-sample performance of the UMV, CMV, and Passive/Managed strategies using all nine lagged information variables in the information set. Table 2 reports the after-cost performance between January 1995 and December 2014 for the UMV, CMV, and Passive/Managed strategies and the two benchmark strategies (1/N and PMV). Panel A of the table reports the Sharpe(1966), CER performance $(\%)$, performance fee $(\Delta, \%)$, Jensen performance $(\alpha, \%)$, and the average turnover. Panels B and C report the $z$-test of equal Sharpe (panel B), and CER (panel C) performance between

\footnotetext{
${ }^{14}$ The low $\mathrm{R}^{2} \mathrm{~s}$ from predictive regressions are still a challenge for rational asset pricing models to explain (Zhou(2010), Huang and Zhou(2015)).
} 
every pair of strategies. Where the $z$-test is negative (positive) in panels B and C, implies that the strategy in the row has a lower (higher) Sharpe or CER performance than the strategy in the column. All of the test statistics in Table 2 onwards are corrected for the effects of heteroskedasticity and serial correlation using the automatic lag selection (without prewhitening) method of Newey and West(1994). To conserve space, we do not report the $z$ test of the performance fees or the $t$-statistic of the Jensen performance but we do denote statistical significance.

Table 2 here

Table 2 shows that none of the dynamic trading strategies significantly outperform the 1/N strategy using all the lagged information variables. The $1 / \mathrm{N}$ strategy actually provides a significant higher Sharpe performance than the Passive/Managed and CMV strategies. The Passive/Managed, CMV, and UMV strategies all have significant negative Jensen performance. The Passive/Managed strategy has extremely high average turnover. The high turnover and poor performance of the Passive/Managed strategy is due to the large number of lagged information variables, which increases the estimation risk of this strategy.

In contrast to the Passive/Managed and CMV strategies, the UMV strategy has a much lower negative Jensen performance and lower turnover. The lower turnover stems from the conservative response the UMV strategy has to extreme values of the lagged information variables (Ferson and Siegel(2001), and Abhyankar et al(2012)). The UMV strategy does significantly outperform the Passive/Managed and CMV strategies using both the Sharpe and CER measures. These findings are similar to Fletcher(2011).

The results in Table 2 suggest that although the UMV strategy does outperform the alternative dynamic trading strategies, it does not significantly outperform the $1 / \mathrm{N}$ strategy 
after adjusting for trading costs. We next examine the performance of the dynamic trading strategies, where we consider the two subsets of the lagged information variables. The first subset is the three lagged information variables with the highest persistence $(\rho)$ level in the initial estimation window (DY, $\mathrm{R}_{\mathrm{f}}$, and Term) and the second subset is the three lagged information variables with the highest predictability in the initial estimation window $(\Omega)$ (Default, Market, and US Market). Table 3 reports the out-of-sample performance of the strategies using the two subsets of the lagged information variables. Panel A refers to the lagged information variables with the highest $\rho$ and panel B refers to the lagged information variables with the highest $\Omega$. To examine whether the choice of lagged information variables has a significant impact on the performance of the UMV strategy, panel C reports the $z$-tests of equal Sharpe (columns 2 and 3) and CER (columns 5 and 6) performance measures between the UMV strategies using all the lagged information variables (All), and the two subsets of lagged information variables.

Table 3 here

Panel A of Table 3 shows that the UMV strategy is the only mean-variance strategy with positive performance across all performance measures when using the lagged information variables with the highest $\rho$. The UMV strategy also has the lowest average turnover among the mean-variance strategies. The negative performance of the Passive/Managed strategy in panel A is substantially reduced compared to Table 2 , as is the average turnover of the strategy. The UMV strategy significantly outperforms the PMV, Passive/Managed, and CMV strategies using the Sharpe measure and the PMV strategy using the CER measure. The outperformance of the UMV strategy relative to the different meanvariance strategies is driven by a lower turnover and a superior performance before trading 
costs. Although the UMV strategy does outperform the alternative dynamic trading strategies, it does not provide significant outperformance relative to the $1 / \mathrm{N}$ strategy or exhibit significant positive Jensen performance.

When using the lagged information variables with the highest $\Omega$ in panel B of Table 3 , there is a sharp increase in the average turnover for all three dynamic trading strategies and the performance of the Passive/Managed and UMV strategies is poorer than compared in panel A of Table 3. The average turnover of the UMV strategy more than doubles compared to panel A. All three dynamic trading strategies in panel B have negative Sharpe and CER performance. The $1 / \mathrm{N}$ strategy provides a significant higher Sharpe performance than all the other strategies. Among the dynamic trading strategies, the UMV strategy significantly outperforms the Passive/Managed and CMV strategies using the CER measure, and the CMV strategy using the Sharpe measure.

Panel $\mathrm{C}$ of Table 3 provides the formal tests of whether the choice of the lagged information variables has a significant impact on the after-cost performance of the UMV strategy. Panel C shows that the UMV strategy using the lagged information variables with the highest persistence level provide a significant higher after-cost performance using the Sharpe and CER measures relative to the other two UMV strategies. This result suggests that using lagged information variables with the highest persistence levels enhances the after-cost performance of the UMV strategy. This finding is driven by the lower turnover of using the lagged information variables with the highest persistence levels as the before-cost performance between the UMV strategies is similar using either the Sharpe or CER measures. The use of persistent lagged information variables lowers the turnover of the UMV strategy because the conditional expected excess returns is less volatile through time compared to using lagged information variables with a lower persistence level (Abhyankar et al(2012)). 
Our findings that the superior after-cost performance of the UMV strategy relative to the Passive/Managed and CMV strategies is similar to Fletcher(2011) in U.K. stock returns, although the test assets and sample period differs. The benefits of the UMV strategy relative to the alternative dynamic trading strategies are similar to Ferson and Siegel(2009) and Abhyankar et al(2012). The poor performance of the Passive/Managed strategy is consistent with Stivers and Sun(2014). The lack of significant Jensen performance shows that dynamic trading strategies do not deliver significant value added for investors and is similar to the neutral closed-end fund Jensen performance in Fletcher and Marshall(2014).

We conduct a number of robustness tests on our performance tests of the UMV strategy using the lagged information variables with the highest persistence levels. First, we examine if there are any benefits for the UMV strategy of using a time-varying conditional covariance matrix. We model a time-varying conditional covariance matrix using the two alternative approaches of Ferson and Siegel(2009) ${ }^{15}$. We find that using a time-varying conditional covariance matrix has little impact on the performance of the UMV strategy and actually leads to a marginal reduction in out-of-sample performance. Second, we examine the impact of portfolio constraints on the performance of the UMV strategy by imposing no short selling restrictions by truncating the negative weights in the UMV strategy to zero. We also consider the impact of no short selling and an upper bound constraint of 0.4 . There is a marginal reduction in the performance of the UMV strategy but the differences are not statistically significant. Imposing constraints has no significant impact on the performance of the UMV strategy. Third, we examine the impact of using a higher target expected excess returns for the strategies. Using a higher target expected excess returns does increase the turnover of the strategies but also increases the before-cost performance and so our main findings are largely unchanged.

${ }^{15}$ Details are provided in the Appendix. 
We next examine the performance of the mean-variance strategies over different subperiods using the three lagged information variables with the highest persistence levels. We consider three different subperiods ${ }^{16}$. First, we split the overall sample period into a precrisis period (January 1995 and December 2006), and a post-crisis period (January 2007 and December 2014). Second, we split the sample period into recession and expansion states using the formal definition of a recession in the U.K. economy ${ }^{17}$. Third, we split the sample period into bearish and bullish market states following Zhang(2012). Bearish market states are the months in the lowest $30 \%$ of excess market returns and bullish market states are the months in the highest $30 \%$ of excess market returns over the January 1995 and December 2014 period $^{18}$. Table 4 reports the subperiod performance of the mean-variance strategies. To conserve space, we do not report the $z$-tests of equal Sharpe and CER performance between the strategies but discuss in the text.

\section{Table 4 here}

Panel A of Table 4 shows that the performance of the dynamic trading strategies is better in the pre-2007 period. The UMV and Passive/Managed strategies have the best performance in the first subperiod and have positive performance across all measures. However neither strategy significantly outperforms the $1 / \mathrm{N}$ strategy. The UMV strategy does provide a significant higher performance than the CMV strategy using the Sharpe and CER

\footnotetext{
${ }^{16} \mathrm{We}$ are thankful for the reviewers in suggesting that we examine this issue in more detail.

${ }^{17}$ Recession occurs when there are two successive quarters of negative real GDP growth. We define recession states for the months within the quarters where there is a recession.

${ }^{18}$ Drenovak, Urosevic and Jelic(2014) and Leite and Cortez(2015) find that the performance of funds is sensitive to crisis periods.
} 
measures. For the second subperiod, the performance of the mean-variance strategies deteriorates. The Passive/Managed and CMV strategies have large negative performance. In contrast the UMV strategy has a performance close to zero. The differences in performance between the UMV strategy and the other three mean-variance strategies are large in economic terms but the differences are not statistically significant due to large standard errors. The difference in performance between the two subperiods for the UMV strategy is driven mainly by a lower turnover in the first subperiod. The before-cost performance of the UMV strategy is a bit lower in the second subperiod in contrast to the other mean-variance strategies where the before-cost performance in the second subperiod is poor. Coupled with a much higher turnover in the second subperiod, the PMV, Passive/Managed, and CMV strategies have poor after-cost performance in the second subperiod.

Panel B of Table 4 shows that the performance of the UMV strategy is stronger in recession states and delivers positive performance across all measures. In contrast all the other strategies deliver negative performance in recession states with the PMV and CMV strategies having particularly poor performance. The UMV strategy significantly outperforms the PMV, Passive/Managed, and CMV strategies using the Sharpe measure amd the PMV and Passive/Managed strategies using the CER measure. There is substantial improvement in the performance of all strategies except the UMV strategy in expansion states. The UMV strategy continues to have positive performance across all measures. The UMV strategy provides a significant higher Sharpe and CER performance than the CMV strategy and a significant higher CER performance than the PMV strategy. The difference in performance between the recession and expansion states for the UMV strategy is driven entirely by a much higher before-cost performance in recession states as the turnover of the UMV strategy in recession states is more than double the turnover in expansion states. The alternative strategies have both a poor before-cost performance and a much higher turnover in 
recession states, which explain the poor after-cost performance in recession states in panel B of Table 4 .

Panel $\mathrm{C}$ of Table 4 shows that the performance of the UMV strategy is relatively robust across bearish and bullish market states. In bearish market states the UMV strategy is the only strategy that delivers close to neutral performance using the Sharpe and CER measures. The UMV strategy provides a significant higher performance than the $1 / \mathrm{N}$ and PMV strategies using the Sharpe and CER measures and a significant higher CER performance than the Passive/Managed strategy. Three of the four mean-variance strategies have significant performance fees. The performance of all the strategies tends to improve in bullish market states, especially for the $1 / \mathrm{N}$ and CMV strategies. Among the mean-variance strategies the UMV strategy still has the best performance. There are no significant differences in the Sharpe and CER performance between the mean-variance strategies but the $1 / \mathrm{N}$ strategy significantly outperforms all the mean-variance strategies using both measures in bullish market states. The performance of the UMV strategy is stronger in bullish market states due to a better before-cost performance since the turnover of the UMV strategy is marginally higher in bullish market states. The UMV strategy has superior after-cost performance in bearish market states relative to the alternative strategies due to both a much lower turnover (excluding the $1 / \mathrm{N}$ strategy) and much better before-cost performance.

The results in Table 4 suggest that the UMV strategy, when using the lagged information variables with the highest persistence levels, delivers the most consistent subperiod performance across the strategies. The relative performance of the UMV strategy is particularly strong in recession states and bearish market states. The UMV strategy is even able to significantly outperform the $1 / \mathrm{N}$ strategy in bearish market states. This result suggests that the optimal use of return predictability is especially beneficial in periods of poor market performance. This finding is driven by lower turnover and superior before-cost 
performance of the UMV strategy. Although the UMV strategy performs well across subperiods, it does not provide a significant positive Jensen performance.

Our analysis so far assumes that the trading costs are 50 basis points. We next examine the performance of the mean-variance strategies assuming a level of proportional cost per transaction of 10 basis points as in DeMiguel et al(2014). Table 5 reports the performance of the mean-variance strategies over the whole sample period using the lagged information variables with the highest persistence levels. Table 6 reports the corresponding subperiod performance.

Table 5 here

Table 6 here

Table 5 shows that when the investor faces lower trading costs at 10 basis points, there is a dramatic improvement in the performance of the UMV strategy. The UMV strategy now delivers a significant positive Jensen performance and significantly outperforms all the other mean-variance strategies using the Sharpe measure. The UMV strategy also provides a significant higher CER performance than the CMV strategy. Much of the negative performance of the Passive/Managed strategy from Panel A of Table 3 also disappears at the lower level of trading costs.

Table 6 shows that the subperiod performance of the UMV strategy is robust at the lower level of trading costs. The performance of all the strategies improves at the lower trading costs. The UMV strategy is the only strategy to have positive performance across all subperiods. The UMV strategy has the highest Sharpe performance across all strategies except in bullish market states. The UMV strategy is able to significantly outperform the $1 / \mathrm{N}$ strategy using the Sharpe and CER measures in bearish market states. The UMV strategy 
provides a significant positive Jensen performance in the pre-2007 and post-2007 subperiods and in recession and expansion states suggesting that the optimal use of return predictability in closed-end fund portfolios delivers significant value added to investors.

The results in Tables 5 and 6 suggest that when investors face lower trading costs, the UMV strategy in closed-end fund portfolios, using the most persistent lagged information variables, can deliver significant value added to investors. This result stems from the fact the UMV strategy has superior before-cost performance and lower turnover compared to the alternative strategies. The finding that the UMV strategy adds value is interesting given the mixed empirical evidence as to whether individual closed-end funds can deliver significant value added to investors. Fletcher and Marshall(2014) find that investment sector portfolios of closed-end funds have neutral performance and there are no funds with either significant superior or inferior performance beyond what we would expect in a world with zero performance. Bredin, Cuthbertson, Nitzsce and Thomas(2014) find more positive results about the performance of closed-end funds. However their sample of funds includes both domestic and international equity funds and they use both self-designated benchmarks and global factors to evaluate performance. Our study suggests that closed-end funds provide a useful investment vechicle for investors from the optimal use of return predictability with lagged information variables with the highest persistence levels.

\section{Conclusions}

We examine whether the choice of the lagged information variables affects the aftercost performance of the UMV strategy in U.K. equity closed-end fund portfolios. There are three main findings in our study. First, we find that the choice of lagged information variables has a significant impact on the after-cost performance of the UMV strategy. The UMV strategy, using the three lagged information variables with the highest persistence levels, significantly outperforms the UMV strategies using all lagged information variables 
and the three lagged information variables with the highest predictability. The superior performance is driven by lower average turnover and not superior before-cost performance. The UMV strategy is able to significantly outperform after adjusting for trading costs the alternative dynamic trading strategies and the PMV strategy using the lagged information variables with the highest persistence levels. This superior performance is driven by both a lower turnover and a superior before-cost performance. The benefits of the optimal use of return predictability is consistent with Ferson and Siegel(2009), Fletcher(2011), Abhyankar et al(2012), and Penaranda(2014) among others. However the UMV strategy does not significantly outperform the $1 / \mathrm{N}$ strategy.

Second, we find that the UMV strategy, using the lagged information variables with the highest persistence levels, have the most consistent subperiod performance across all strategies. The UMV strategy provides particularly good performance in recession states and bearish market states. The UMV strategy is able to significantly outperform the $1 / \mathrm{N}$ strategy in bearish market states. The subperiod performance suggests that the optimal use of return predictability delivers good performance in low market states and suggests it provides a hedge against market downturns. This superior performance is driven by both a lower turnover and superior before-cost performance.

Third, we find at lower levels of trading costs of 10 basis points, the UMV strategy using the lagged information variables with the highest persistence levels delivers significant value added to investors. The UMV strategy also provides a significant higher Sharpe performance relative to the alternative mean-variance strategies. The UMV strategy continues to have good subperiod performance and delivers significant value added to investors in both the pre-2007 and post-2007 subperiods, and in recession and expansion states. This finding is consistent with DeMiguel et al(2014) who find that the benefits of using conditioning information in CMV strategies only holds at low levels of trading costs. 
Our results suggest that using lagged information variables with the highest persistence levels is an effective way of reducing the turnover of the UMV strategy and exploit the benefits of the optimal use of return predictability. At low levels of trading costs, the UMV strategy delivers significant value added to investors. This result suggests the U.K. equity closed-end funds can be a useful investment vehicle even where the underlying funds have neutral performance (Fletcher and Marshall(2014)). Our results also suggest that closed-end fund managers might wish to consider exploiting the optimal use of return predictability in their trading strategies using lagged information variables with the highest persistence levels.

Our analysis has focused on portfolios of domestic equity closed-end funds. An interesting extension to our study would be to examine the performance of the UMV strategy using individual closed-end funds. It would be useful to see if the UMV strategy performs well in portfolios of international equity closed-end funds. Exploring the benefits of the optimal use of return predictability in other types of managed funds such as open-end funds or hedge funds is worthy of investigation. We leave these issues to future research. 


\section{Appendix}

\section{A) Factors in the Carhart(1997) Model}

We form the factors between January 1990 and December 2014. We construct the market index using a similar approach to Dimson and Marsh(2001). At the start of each year between 1990 and 2014, we construct a value weighted portfolio of all stocks on LSPD by their market value at the start of the year. We calculate buy and hold monthly returns during the next year. We exclude companies with a zero market value. We make a number of corrections and exclusions to the portfolio returns which we follow across forming the factors and the passive portfolios. Where a security has missing return observations during the year or month, we assign a zero return to the missing values as in Liu and Strong(2008). We correct for the delisting bias of Shumway(1997) by following the approach of Dimson, Nagel and Quigley(2003). A $-100 \%$ return is assigned to the death event date on LSPD where the LSPD code indicates that the death is valueless. We exclude closed-end funds, foreign companies, and secondary shares using data from the LSPD archive file.

To form the SMB and HML factors we use a similar approach to Fama and French(2012). At the start of July year between 1989 and 2014, all stocks on LSPD are ranked separately by their market value at the end of June and by their book-to-market (BM) ratio from the prior calendar year. The BM ratio is calculated using the book value of equity at the fiscal year-end (WC03501) during the previous calendar year from Worldscope and the year-end market value. Two size groups (Small and Big) are formed using a breakpoint of $90 \%$ by aggregate market capitalization where the Small stocks are the companies with smallest $10 \%$ by market value and the Big stocks are the companies with the largest $90 \%$ by market value. Three BM groups (Growth, Neutral, and Value) are formed using break points of the $30^{\text {th }}$ and $70^{\text {th }}$ percentiles of the BM ratios of Big stocks. Six portfolios of securities are then constructed at the intersection of the size and BM groups ( $\mathrm{SG}, \mathrm{SN}, \mathrm{SV}, \mathrm{BG}, \mathrm{BN}, \mathrm{BV})$. 
The monthly buy and hold return for the six portfolios are then calculated during the next 12 months. The initial weights are set equal to the market value weights at the end of June. Companies with a zero market value, and negative book values are excluded.

The SMB factor is the difference in the average return of the three small firm portfolios (SG, SN, SV) and the average return of the three large firm portfolios (BG, $\mathrm{BN}$, BV). The HML factor is the average of $H M L_{S}$ and $H M L_{B}$ where $H M L_{S}$ is the difference in portfolio returns of $\mathrm{SV}$ and $\mathrm{SG}$ and $\mathrm{HML}_{\mathrm{B}}$ is the difference in portfolio returns of $\mathrm{BV}$ and BG. The HMLs and HML $\mathrm{H}_{\mathrm{B}}$ zero-cost portfolios capture the value effect in Small stocks and Big stocks respectively.

We form the WML factor using a similar approach to Fama and French(2012). At the start of each month between January 1990 and December 2014, all stocks on LSPD are ranked separately by their market value at the end of the previous month and on the basis of their cumulative return from months -12 to -2 . Two size groups (Small and Big) are formed as in the case of the size/BM portfolios. Three past return groups (Losers, Neutral, and Winners) are formed using break points of the $30^{\text {th }}$ and $60^{\text {th }}$ percentiles of the past returns of Big stocks. Six portfolios of securities are then constructed at the intersection of the size and momentum groups (SL, SN, SW, BL, BN, BW). The value weighted return for the six portfolios are then calculated during the next month. Companies with a zero market value, and less than 12 return observations during the past year are excluded from the portfolios.

The WML factor is the average of $\mathrm{WML}_{\mathrm{S}}$ and $\mathrm{WML}_{\mathrm{B}}$ where $\mathrm{WML}_{\mathrm{S}}$ is the difference in portfolio returns of $\mathrm{SW}$ and $\mathrm{SL}$ and $\mathrm{WML}_{\mathrm{B}}$ is the difference in portfolio returns of $\mathrm{BW}$ and BL. The WMLs and $\mathrm{WML}_{\mathrm{B}}$ zero-cost portfolios capture the momentum effect in Small stocks and Big stocks respectively.

\section{B) Lagged Information Variables}


The term spread is the difference in the annualized yield on long-term government bonds and the three-month Treasury Bill. The U.K. long-term bond yield comes from the International Financial Statistics (IFS) U.K. country tables provided by the International Monetary Fund (IMF). The default spread is the difference in price returns of U.K. corporate bond and government bond indexes. The corporate bond index consists of the Financial Times (FT) Fixed Interest Securities index until it discontinues and the Barclays Capital Sterling Aggregate Corporate bond index. The government bond index consists of the FT Government Securities index until it discontinues and the Barclays Capital Sterling Aggregate Government bond index. The index series are collected from Datastream. We calculate the output gap using the seasonally adjusted U.K. industrial production index provided by the IFS. We estimate the output gap using the recursive approach as in Cooper and Priestley(2009). We calculate the lagged monthly log quarterly growth in the Baltic Dry Index (BDI) following the approach of Bakshi et al(2014). For the excess returns on the U.S. market index, we use the value weighted market index and the one-month Treasury Bill return available on the Ken French's Data Library ${ }^{19}$.

\section{C) Models of Conditional Moments}

We consider two alternative models of conditional moments as in Ferson and Siegel(2009). In each model, the conditional expected excess returns are the same as the predictive regression model but both models provide an estimate of a time varying conditional covariance matrix.

1) Conditional single-index model

This model uses a conditional single-index model to model the conditional covariance matrix. The conditional covariance matrix can be calculated from a conditional $\mathrm{K}$ factor model as:

\footnotetext{
${ }^{19} \mathrm{http} / / / \mathrm{mba} . t u c k . d a r t m o u t h . e d u / p a g e s /$ faculty/ken.french/data_library.html
} 


$$
\Sigma_{\mathrm{t}}=\beta_{\mathrm{t}}{ }^{\prime} \Sigma_{\mathrm{ft}} \beta_{\mathrm{t}}+\Sigma_{\mathrm{ut}}
$$

where $\beta_{\mathrm{t}}$ is a $(\mathrm{N}, \mathrm{K})$ matrix of the conditional betas on the $\mathrm{K}$ factors at time $\mathrm{t}, \Sigma_{\mathrm{ft}}$ is a $(\mathrm{K}, \mathrm{K})$ conditional covariance matrix of the $\mathrm{K}$ factors at time $\mathrm{t}, \Sigma_{\mathrm{ut}}$ is the $(\mathrm{N}, \mathrm{N})$ conditional residual covariance matrix at time $\mathrm{t}$, and $\mathrm{K}$ is the number of factors. For this model of the conditional moments $\mathrm{K}=1$ and we use the excess stock market returns as the single-index.

The conditional betas are assumed to be a linear function of $\mathrm{Z}_{\mathrm{t}}$. We estimate the conditional beta function from the regression of the residuals from the predictive regression on a constant, the excess market returns, and the scaled excess market returns (excess market returns times the lagged information variables) during the estimation window. We get the conditional betas by multiplying the slope coefficients from this regression by the current values of $Z_{t}$ at the start of the month. We assume $\Sigma_{\mathrm{ut}}$ is constant and use the ML estimate of the sample covariance matrix of the residuals from the conditional beta regression. We assume that the conditional variance of the market excess returns is constant and calculate as the ML estimate of the variance of the residuals from the regression of the excess market returns on $\mathrm{Z}_{\mathrm{t}}$ during the estimation window.

\section{Davidian and Carroll(1987)}

This model assumes that the conditional correlation matrix is constant and models the conditional standard deviations of the $\mathrm{N}$ excess returns. The conditional standard deviations of the $\mathrm{N}$ excess returns are given by the fitted values from the regression of the absolute residuals (from the predictive regression) on $Z_{t}$ multiplied by $(\pi / 2)^{1 / 2}$. We estimate this regression during the estimation window and multiply the coefficients from this regression by the current values of $Z_{t}$ at the start of the month. We then multiply by $(\pi / 2)^{1 / 2}$ to get the conditional standard deviations The conditional correlation matrix is assumed constant and is estimated from the residual correlation matrix from the predictive regression. The 
conditional covariance matrix is then calculated from the corresponding conditional standard deviations and correlation matrix. 
Table 1 Summary Statistics of Closed-End Fund Portfolios and Lagged Information Variables

\begin{tabular}{lrrrrr}
\hline Panel A & Mean & $\begin{array}{r}\text { Standard } \\
\text { Deviation }\end{array}$ & Minimum & Maximum & \\
All Companies & 0.371 & 4.574 & -15.352 & 16.653 & \\
Equity Income & 0.473 & 4.455 & -14.392 & 14.880 & \\
Small & & & & & \\
Companies & 0.479 & 5.809 & -22.459 & 21.893 & \\
Equity and & & & & & \\
Bond Income & 0.008 & 4.943 & -22.214 & 13.581 & \\
\hline & & Standard & & & $0.063^{1}$ \\
Panel B & Mean & Deviation & $\rho_{1}$ & Maximal R & $0.029^{2}$ \\
DY & 3.599 & 0.793 & 0.982 & 0.059 & $0.030^{2}$ \\
Rf & 0.412 & 0.294 & 0.977 & 0.028 & $0.049^{1}$ \\
Term & 0.782 & 1.604 & 0.962 & 0.029 & 0.025 \\
Default & 0.120 & 1.808 & 0.214 & 0.047 & 0.012 \\
Inflation & 0.263 & 0.432 & 0.158 & 0.025 & $0.290^{1}$ \\
Output Gap & -3.846 & 2.705 & 0.938 & 0.012 & 0.025 \\
Market & 0.340 & 3.943 & 0.075 & 0.225 & $0.197^{1}$ \\
BDI & -0.264 & 34.911 & 0.704 & 0.024 & \\
US Market & 0.629 & 4.354 & 0.080 & 0.164 & \\
\hline
\end{tabular}

${ }^{1}$ Significant at $5 \%$

${ }^{2}$ Significant at $10 \%$

The table reports summary statistics of the four U.K. equity closed-end fund portfolios (panel A) and nine lagged information variables (panel B) between January 1990 and December 2014. The summary statistics in panel A of the table are the mean, standard deviation, minimum, and maximum monthly excess returns (\%). The summary statistics in panel B include the mean, standard deviation, and first order autocorrelation $\left(\rho_{1}\right)$ of the lagged information variables. The maximal $\mathrm{R}^{2}$ column is the maximal $\mathrm{R}^{2}$ of $\mathrm{Lo}$ and MacKinlay(1997) from the predictive regressions of the closed-end fund portfolio excess returns on a constant and the corresponding lagged information variable. The final column $(\Omega)$ is the difference between the average ex ante conditional squared Sharpe performance and the squared Sharpe performance of a fixed weight portfolio strategy and captures the hypothetical benefits in the optimal use of predictability (Abhyankar et al(2012)). The null hypothesis of $\Omega=0$ is tested by a standard Wald test as in Proposition 3 of Abhyankar et al. The lagged information variables include the lagged values of the annualized dividend yield (DY) on the market index, the return on the one-month Treasury Bill $\left(\mathrm{R}_{\mathrm{f}}\right)$, the term spread (Term), the default spread (Default), the monthly change in the RPI index (inflation), the output gap, the excess market return (Market), the log quarterly growth in the BDI index (BDI), and lag excess return on the U.S. market (US Market). 
Table 2 After-Cost Performance of Mean-Variance Strategies: All Lagged Information Variables

\begin{tabular}{lrrrrr}
\hline Panel A & Sharpe & CER & $\Delta$ & $\alpha$ & Turnover \\
1/N & 0.089 & -0.085 & & & 0.014 \\
PMV & -0.138 & -0.920 & -0.842 & $-0.975^{2}$ & 0.747 \\
Passive/Managed & -0.244 & -0.666 & -0.579 & $-0.604^{1}$ & 1.611 \\
CMV & -0.272 & -0.208 & -0.119 & $-0.206^{1}$ & 0.655 \\
UMV & -0.112 & -0.084 & 0.004 & $-0.096^{2}$ & 0.498 \\
\hline Panel B: & & & & \\
Sharpe & PMV & Passive/Managed & $\mathrm{CMV}$ & $\mathrm{UMV}$ & \\
1/N & $2.01^{1}$ & $3.13^{1}$ & $2.83^{1}$ & 1.50 & \\
PMV & & 0.92 & 1.37 & -0.25 & \\
Passive/Managed & & & 0.41 & $-1.79^{2}$ & \\
CMV & & & & $-5.91^{1}$ & \\
\hline Panel C: & & & & & \\
CER & PMV & Passive/Managed & CMV & $\mathrm{UMV}$ & \\
1/N & 1.38 & 1.36 & 0.28 & -0.00 & \\
PMV & & -0.57 & -1.37 & -1.63 & \\
Passive/Managed & & & $-2.65^{1}$ & $-3.44^{1}$ & \\
CMV & & & $-3.85^{1}$ & \\
\hline
\end{tabular}

${ }^{1}$ Significant at $5 \%$
${ }^{2}$ Significant at $10 \%$

The table reports the out-of-sample after-cost performance of the $1 / \mathrm{N}, \mathrm{PMV}$, Passive/Managed, CMV, and UMV strategies between January 1995 and December 2014. The investment universe is the excess returns of four U.K. equity closed-end fund portfolios sorted by investment sector and the one-month U.K. Treasury Bill return. The dynamic trading strategies (Passive/Managed, CMV, and UMV) are estimated using all nine lagged information variables. The target conditional and unconditional expected excess return is set equal to $0.5 \%$. A monthly rolling 60 -month estimation window is used. The after-cost performance assumes a level of proportional cost per transaction of 50 basis points. Panel A of the table reports the out-of-sample performance and average turnover of the strategies. The performance measures are the Sharpe(1966) measure, the CER(\%) measure, the performance fee $(\Delta, \%)$ of Kirby and Ostdiek(2012), and the Jensen performance measure $(\alpha, \%)$. Panels B and C report the $z$-test of equal Sharpe (panel B), and CER (panel C) performance between every pair of strategies. All of the test statistics are corrected for the effects of heteroskedasticity and serial correlation using the automatic lag selection (without prewhitening) method of Newey and West(1994). 
Table 3 After-Cost Performance of Mean-Variance Strategies: Subsets of Lagged Information Variables

\begin{tabular}{|c|c|c|c|c|c|}
\hline Panel A: $\boldsymbol{\rho}$ & Sharpe & CER & $\Delta$ & $\alpha$ & Turnover \\
\hline $1 / \mathrm{N}$ & 0.089 & -0.085 & & & 0.014 \\
\hline PMV & -0.138 & -0.920 & -0.842 & $-0.975^{2}$ & 0.747 \\
\hline Passive/Managed & -0.013 & -0.221 & -0.136 & -0.145 & 0.667 \\
\hline CMV & -0.079 & -0.909 & -0.831 & -0.343 & 0.638 \\
\hline UMV & 0.102 & 0.076 & 0.166 & 0.070 & 0.363 \\
\hline$z$-test Sharpe & PMV & Passive/Managed & CMV & UMV & \\
\hline $1 / \mathrm{N}$ & $2.01^{1}$ & 1.09 & $1.92^{2}$ & -0.11 & \\
\hline PMV & & $-1.92^{2}$ & -0.71 & $-2.48^{1}$ & \\
\hline Passive/Managed & & & 1.10 & $-1.70^{2}$ & \\
\hline CMV & & & & $-2.96^{1}$ & \\
\hline z-test CER & PMV & Passive/Managed & CMV & UMV & \\
\hline $1 / \mathrm{N}$ & 1.38 & 0.29 & 0.99 & -0.39 & \\
\hline PMV & & $-2.03^{1}$ & -0.01 & $-1.91^{2}$ & \\
\hline Passive/Managed & & & 0.78 & -1.20 & \\
\hline CMV & & & & -1.17 & \\
\hline Panel B: $\boldsymbol{\Omega}$ & Sharpe & CER & $\Delta$ & $\alpha$ & Turnover \\
\hline $1 / \mathrm{N}$ & 0.089 & -0.085 & & & 0.014 \\
\hline PMV & -0.138 & -0.920 & -0.842 & -0.975 & 0.747 \\
\hline Passive/Managed & -0.257 & -0.317 & -0.227 & -0.287 & 1.210 \\
\hline CMV & -0.328 & -0.405 & -0.316 & -0.387 & 1.250 \\
\hline UMV & -0.158 & -0.162 & -0.072 & -0.172 & 0.820 \\
\hline z-test Sharpe & PMV & Passive/Managed & CMV & UMV & \\
\hline $1 / \mathrm{N}$ & $2.01^{1}$ & $3.07^{1}$ & $2.90^{1}$ & $1.72^{2}$ & \\
\hline PMV & & 0.98 & $1.84^{2}$ & 0.21 & \\
\hline Passive/Managed & & & 0.71 & -1.11 & \\
\hline CMV & & & & $-3.94^{1}$ & \\
\hline z-test CER & PMV & Passive/Managed & CMV & UMV & \\
\hline $1 / \mathrm{N}$ & 1.38 & 0.57 & 0.74 & 0.17 & \\
\hline PMV & & -1.16 & -0.99 & -1.51 & \\
\hline Passive/Managed & & & 0.91 & $-2.18^{1}$ & \\
\hline CMV & & & & $-4.08^{1}$ & \\
\hline $\begin{array}{l}\text { Panel C: } \\
\boldsymbol{z} \text {-test Sharpe }\end{array}$ & $\rho$ & $\Omega$ & z-test CER & $\rho$ & $\Omega$ \\
\hline All & $-3.74^{1}$ & 0.81 & All & $-3.55^{1}$ & 1.60 \\
\hline$\rho$ & & $3.37^{1}$ & $\rho$ & & $3.56^{1}$ \\
\hline
\end{tabular}

${ }^{1}$ Significant at 5\%

${ }^{2}$ Significant at $10 \%$ 
The table reports the out-of-sample after-cost performance of the $1 / \mathrm{N}, \mathrm{PMV}$, Passive/Managed, CMV, and UMV strategies between January 1995 and December 2014. The investment universe is the excess returns of four U.K. equity closed-end fund portfolios sorted by investment sector and the one-month U.K. Treasury Bill return. The dynamic trading strategies are estimated using the three lagged information variables with the highest persistence levels $(\rho)\left(D Y, R_{f}\right.$, and Term) in panel A, and the three lagged information variables with the highest predictability $(\Omega)$ (Default, Market, and US Market) in panel B from the initial estimation window. The target conditional and unconditional expected excess return is set equal to $0.5 \%$. A monthly rolling 60 -month estimation window is used. The after-cost performance assumes a level of proportional cost per transaction of 50 basis points. Panels A and B of the table report the out-of-sample performance and average turnover of the strategies. The performance measures are the Sharpe(1966) measure, the CER(\%) measure, the performance fee $(\Delta, \%)$ of Kirby and Ostdiek(2012), and the Jensen performance measure $(\alpha, \%)$. The $z$-test Sharpe and $z$-test CER are the $z$-test statistics of equal Sharpe or CER performance between every pair of strategies. Panel $\mathrm{C}$ report the $z$-tests of equal Sharpe and CER performance between the UMV strategies in panels A and B, and the UMV strategy using all lagged information variables (All). All of the test statistics are corrected for the effects of heteroskedasticity and serial correlation using the automatic lag selection (without prewhitening) method of Newey and West(1994). 
Table 4 After-Cost Performance of Mean-Variance Strategies: Subperiod Results

\begin{tabular}{|c|c|c|c|c|}
\hline \multicolumn{5}{|l|}{ Panel A } \\
\hline Jan 1995 and Dec 2006 & Sharpe & CER & $\Delta$ & $\alpha$ \\
\hline $1 / \mathrm{N}$ & 0.077 & -0.141 & & \\
\hline PMV & -0.004 & -0.212 & -0.060 & -0.155 \\
\hline Passive/Managed & 0.128 & 0.133 & 0.287 & 0.108 \\
\hline CMV & -0.009 & -0.036 & 0.119 & -0.061 \\
\hline UMV & 0.163 & 0.147 & 0.302 & 0.107 \\
\hline Jan 2007 and Dec 2014 & Sharpe & CER & $\Delta$ & $\alpha$ \\
\hline $1 / \mathrm{N}$ & 0.107 & -0.000 & & \\
\hline PMV & -0.264 & -1.956 & -1.974 & $-1.920^{1}$ \\
\hline Passive/Managed & -0.093 & -0.747 & -0.758 & -0.428 \\
\hline CMV & -0.125 & -2.206 & -2.254 & -0.687 \\
\hline UMV & -0.011 & -0.026 & -0.032 & 0.018 \\
\hline \multicolumn{5}{|l|}{ Panel B } \\
\hline Recession States & Sharpe & CER & $\Delta$ & $\alpha$ \\
\hline $1 / \mathrm{N}$ & -0.005 & -1.365 & & \\
\hline PMV & -0.763 & -8.180 & -6.884 & $-5.084^{1}$ \\
\hline Passive/Managed & -0.115 & -2.900 & -1.593 & -0.022 \\
\hline CMV & -0.299 & -11.216 & -10.798 & $-6.516^{1}$ \\
\hline UMV & 0.135 & 0.118 & 1.422 & 0.1982 \\
\hline Expansion States & Sharpe & CER & $\Delta$ & $\alpha$ \\
\hline $1 / \mathrm{N}$ & 0.105 & 0.018 & & \\
\hline PMV & -0.022 & -0.256 & -0.271 & -0.302 \\
\hline Passive/Managed & 0.031 & -0.002 & -0.016 & -0.015 \\
\hline CMV & -0.009 & -0.030 & -0.042 & -0.040 \\
\hline UMV & 0.099 & 0.073 & 0.060 & 0.051 \\
\hline \multicolumn{5}{|l|}{ Panel C } \\
\hline Bearish Market States & Sharpe & CER & $\Delta$ & $\alpha$ \\
\hline $1 / \mathrm{N}$ & -1.033 & -4.554 & & \\
\hline PMV & -0.512 & -2.397 & $2.142^{1}$ & -0.166 \\
\hline Passive/Managed & -0.119 & -0.289 & $4.198^{1}$ & -0.379 \\
\hline CMV & -0.128 & -2.733 & 1.994 & 0.495 \\
\hline UMV & 0.021 & -0.003 & $4.476^{1}$ & -0.121 \\
\hline Bullish Market States & Sharpe & CER & $\Delta$ & $\alpha$ \\
\hline $1 / \mathrm{N}$ & 1.637 & 4.033 & & \\
\hline PMV & 0.062 & -0.377 & -4.604 & -0.900 \\
\hline Passive/Managed & 0.032 & -0.360 & -4.515 & -2.509 \\
\hline CMV & 0.110 & 0.089 & -3.910 & 0.238 \\
\hline UMV & 0.210 & 0.210 & -3.792 & 0.330 \\
\hline
\end{tabular}

${ }^{1}$ Significant at 5\%

${ }^{2}$ Significant at $10 \%$ 
The table reports the out-of-sample after-cost performance of the $1 / \mathrm{N}, \mathrm{PMV}$, Passive/Managed, CMV, and UMV strategies across the different subperiods. The investment universe is the excess returns of four U.K. equity closed-end fund portfolios sorted by investment sector and the one-month U.K. Treasury Bill return. The dynamic trading strategies (Passive/Managed, CMV, and UMV) are estimated using the three lagged information variables with the highest persistence levels (DY, $\mathrm{R}_{\mathrm{f}}$, and Term) in the initial estimation window. The target conditional and unconditional expected excess return is set equal to $0.5 \%$. A monthly rolling 60 -month estimation window is used. The after-cost performance assumes a level of proportional cost per transaction of 50 basis points. The performance measures are the Sharpe(1966) measure, the CER(\%) measure, the performance fee $(\Delta, \%)$ of Kirby and Ostdiek(2012), and the Jensen performance measure $(\alpha, \%)$. Panel A reports the subperiod performance between January 1995 and December 2006 and January 2007 and December 2014. Panel B reports the subperiod performance of recession and expansion states. Panel $\mathrm{C}$ reports the subperiod performance of bearish and bullish market states. All of the test statistics are corrected for the effects of heteroskedasticity and serial correlation using the automatic lag selection (without prewhitening) method of Newey and West(1994). 
Table 5 After-Cost Performance of Mean-Variance Strategies with Lower Trading Costs

\begin{tabular}{lrrrr}
\hline Panel A & Sharpe & CER & $\Delta$ & $\alpha$ \\
/N & 0.090 & -0.079 & & \\
PMV & -0.067 & -0.593 & -0.518 & -0.670 \\
Passive/Managed & 0.090 & 0.070 & 0.150 & 0.139 \\
CMV & -0.037 & -0.597 & -0.521 & -0.141 \\
UMV & 0.257 & 0.223 & 0.307 & $0.221^{1}$ \\
\hline Panel B & & & & \\
z-test Sharpe & PMV & Passive/Managed & CMV & UMV \\
1/N & 1.37 & 0.00 & 1.42 & -1.52 \\
PMV & & $-2.54^{1}$ & -0.33 & $-3.32^{1}$ \\
Passive/Managed & & & 1.39 & $-2.00^{1}$ \\
CMV & & & $-4.16^{1}$ \\
\hline Panel C & & & \\
z-test CER & PMV & Passive/Managed & CMV & UMV \\
1/N & -0.86 & -1.42 & -0.92 & -1.23 \\
PMV & & -1.32 & -0.42 & -1.19 \\
Passive/Managed & & & $1.79^{2}$ & 0.46 \\
CMV & & & $-2.58^{1}$ \\
\hline
\end{tabular}

${ }^{1}$ Significant at $5 \%$

${ }^{2}$ Significant at $10 \%$

The table reports the out-of-sample after-cost performance of the $1 / \mathrm{N}, \mathrm{PMV}$, Passive/Managed, CMV, and UMV strategies between January 1995 and December 2014. The investment universe is the excess returns of four U.K. equity closed-end fund portfolios sorted by investment sector and the one-month U.K. Treasury Bill return. The dynamic trading strategies (Passive/Managed, CMV, and UMV) are estimated using the three lagged information variables with the highest persistence level in the initial estimation window (DY, $\mathrm{R}_{\mathrm{f}}$, and Term). The target conditional and unconditional expected excess return is set equal to $0.5 \%$. A monthly rolling 60 -month estimation window is used. The after-cost performance assumes a level of proportional cost per transaction of 10 basis points. Panel A of the table reports the out-of-sample performance of the strategies. The performance measures are the Sharpe(1966) measure, the CER(\%) measure, the performance fee $(\Delta, \%)$ of Kirby and Ostdiek(2012), and the Jensen performance measure $(\alpha, \%)$. Panels B and C report the $z$-test of equal Sharpe (panel B), and CER (panel C) performance between every pair of strategies. All of the test statistics are corrected for the effects of heteroskedasticity and serial correlation using the automatic lag selection (without prewhitening) method of Newey and West(1994). 
Table 6 After-Cost Performance of Mean-Variance Strategies: Subperiod Results and Lower Trading Costs

\begin{tabular}{|c|c|c|c|c|}
\hline \multicolumn{5}{|l|}{ Panel A } \\
\hline Jan 1995 and Dec 2006 & Sharpe & CER & $\Delta$ & $\alpha$ \\
\hline $1 / \mathrm{N}$ & 0.078 & -0.134 & & \\
\hline PMV & 0.055 & -0.041 & 0.103 & 0.013 \\
\hline Passive/Managed & 0.262 & 0.321 & 0.468 & $0.304^{1}$ \\
\hline CMV & 0.144 & 0.111 & 0.259 & 0.077 \\
\hline UMV & 0.282 & 0.268 & 0.416 & $0.231^{1}$ \\
\hline Jan 2007 and Dec 2014 & Sharpe & CER & $\Delta$ & $\alpha$ \\
\hline $1 / \mathrm{N}$ & 0.109 & 0.004 & & \\
\hline PMV & -0.183 & -1.405 & -1.424 & $-1.410^{1}$ \\
\hline Passive/Managed & 0.001 & -0.304 & -0.319 & -0.022 \\
\hline CMV & -0.091 & -1.651 & -1.689 & -0.419 \\
\hline UMV & 0.217 & 0.157 & 0.146 & $0.201^{1}$ \\
\hline \multicolumn{5}{|l|}{ Panel B } \\
\hline Recession States & Sharpe & CER & $\Delta$ & $\alpha$ \\
\hline $1 / \mathrm{N}$ & -0.004 & -1.358 & & \\
\hline PMV & -0.638 & -6.651 & -5.351 & $-3.791^{1}$ \\
\hline Passive/Managed & -0.019 & -1.687 & -0.373 & 0.685 \\
\hline $\mathrm{CMV}$ & -0.273 & -9.191 & -8.358 & -5.471 \\
\hline UMV & 0.410 & 0.409 & 1.706 & $0.471^{2}$ \\
\hline Expansion States & Sharpe & CER & $\Delta$ & $\alpha$ \\
\hline $1 / \mathrm{N}$ & 0.106 & 0.024 & & \\
\hline PMV & 0.051 & -0.050 & -0.071 & -0.110 \\
\hline Passive/Managed & 0.197 & 0.212 & 0.193 & $0.202^{1}$ \\
\hline CMV & 0.172 & 0.131 & 0.113 & $0.118^{2}$ \\
\hline UMV & 0.244 & 0.208 & 0.190 & $0.187^{1}$ \\
\hline \multicolumn{5}{|l|}{ Panel C } \\
\hline Bearish Market States & Sharpe & CER & $\Delta$ & $\alpha$ \\
\hline $1 / \mathrm{N}$ & -1.032 & -4.547 & & \\
\hline PMV & -0.462 & -2.007 & $2.518^{1}$ & 0.114 \\
\hline Passive/Managed & 0.051 & 0.0136 & $4.495^{1}$ & -0.098 \\
\hline CMV & -0.112 & -2.221 & 2.461 & 0.572 \\
\hline UMV & 0.175 & 0.151 & $4.625^{1}$ & -0.011 \\
\hline Bullish Market States & Sharpe & CER & $\Delta$ & $\alpha$ \\
\hline $1 / \mathrm{N}$ & 1.640 & 4.039 & & \\
\hline PMV & 0.147 & 0.106 & -4.101 & -0.918 \\
\hline Passive/Managed & 0.113 & 0.049 & -4.076 & -2.159 \\
\hline CMV & 0.300 & 0.268 & -3.736 & 0.407 \\
\hline UMV & 0.360 & 0.377 & -3.632 & 0.452 \\
\hline
\end{tabular}

${ }^{1}$ Significant at 5\%

${ }^{2}$ Significant at $10 \%$ 
The table reports the out-of-sample after-cost performance of the $1 / \mathrm{N}, \mathrm{PMV}$, Passive/Managed, CMV, and UMV strategies across the different subperiods. The investment universe is the excess returns of four U.K. equity closed-end fund portfolios sorted by investment sector and the one-month U.K. Treasury Bill return. The dynamic trading strategies (Passive/Managed, CMV, and UMV) are estimated using the three lagged information variables with the highest persistence levels (DY, $\mathrm{R}_{\mathrm{f}}$, and Term) in the initial estimation window. The target conditional and unconditional expected excess return is set equal to $0.5 \%$. A monthly rolling 60 -month estimation window is used. The after-cost performance assumes a level of proportional cost per transaction of 10 basis points. The performance measures are the Sharpe(1966) measure, the CER(\%) measure, the performance fee $(\Delta, \%)$ of Kirby and Ostdiek(2012), and the Jensen performance measure $(\alpha, \%)$. Panel A reports the subperiod performance between January 1995 and December 2006 and January 2007 and December 2014. Panel B reports the subperiod performance of recession and expansion states. Panel $\mathrm{C}$ reports the subperiod performance of bearish and bullish market states. All of the test statistics are corrected for the effects of heteroskedasticity and serial correlation using the automatic lag selection (without prewhitening) method of Newey and West(1994). 


\section{References}

Abhyankar, A. Basu, D. and A. Stremme, 2012, The optimal use of return predictability: An empirical study, Journal of Financial and Quantitative Analysis, 47, 973-1001.

Andriosopoulos, D., Fletcher, M.H., and A. Marshall, 2015, Non-US closed-end funds,

Baker, H.K., Filbeck, G. and H. Kiymaz (eds) Mutual funds and exchange-traded funds: Building blocks to wealth, Oxford University Press, Oxford, 137-152.

Aragon, G. and W.E. Ferson, 2008, Portfolio performance evaluation, Foundations and Trends in Finance, 2, 83-190.

Avramov, D., Kosowski, R., Naik, N. and M. Teo, 2011, Hedge funds, managerial skill, and macroeconomic variables, Journal of Financial Economics, 99, 672-692.

Avramov, D. and R. Wermers, 2006, Investing in mutual funds when returns are predictable, Journal of Financial Economics, 81, 339-377.

Bakshi, G., Panayotov, G., and G. Skoulakis, 2014, The Baltic Dry index as a predictor of global stock returns, commodity returns, and global economic activity, Working Paper, University of Maryland.

Banegas, A., Gillen, B., Timmermann, A. and R. Wermers, 2013, The cross-section of conditional mutual fund performance in European stock markets, Journal of Financial Economics, 108, 699-726.

Bansal, R., Dahlquist, M. and C.R. Harvey, 2004, Dynamic strategies and portfolio choice, Working Paper, National Bureau of Economic Research.

Berk, J.B. and R. Stanton, 2007, Managerial ability, compensation, and the closed-end fund discount, Journal of Finance, 62, 529-556.

Brandt, M.W. and P. Santa-Clara, 2006, Dynamic portfolio selection by augmenting the asset space, Journal of Finance, 61, 2187-2217. 
Bredin, D., Cuthbertson, K., Nitzsche, D. and D.C. Thomas, 2014, Performance and performance persistence of UK closed-end equity funds, International Review of Financial Analysis, 34, 189-199.

Brown, S. J., Goetzmann, W.N., Ibbotson, R. and S.A. Ross, 1992, Survivorship bias in performance studies, Review of Financial Studies, 5, 553-580.

Carhart, M. M., 1997. Persistence in mutual fund performance. Journal of Finance, 52, 57-82.

Carhart, M.M., Carpenter, J.N., Lynch, A.W. and D.K. Musto, 2002, Mutual fund survivorship, Review of Financial Studies, 15, 1439-1463.

Cherkes, M., 2012, Closed-end funds : A survey, Annual Review of Financial Economics, 4, $431-445$.

Cherkes, M., Sagi, J. and R. Stanton, 2009, A liquidity-based theory of closed-end funds, Review of Financial Studies, 22, 257-297.

Chiang, I.H.E, 2015, Modern portfolio management with conditioning information, Journal of Empirical Finance, 33, 114-134.

Cochrane, J.H., 2005, Asset pricing: Revised Edition, Princeton University Press.

Cooper, I. and R. Priestley, 2009, Time-varying risk premiums and the output gap, Review of Financial Studies, 22, 2801-2833.

Davidian, M. and R.J. Carroll, 1987, Variance function estimation, Journal of the American Statistical Association, 82, 1079-1091.

DeMiguel, V., Garlappi, L. and R. Uppal, 2009, Optimal versus naïve diversification: How inefficient is the 1/N portfolio strategy?, Review of Financial Studies, 22, 1915-1953.

DeMiguel, V., Nogales, F.J. and R. Uppal, 2014, Stock return serial dependence and out-ofsample portfolio performance, Review of Financial Studies, 27, 1031-1073.

Dimson, E. and P.R. Marsh, 2001, U.K. financial market returns 1955-2000, Journal of Business 74, 1-31. 
Dimson, E. and C. Minio-Paluello, 2002, The closed-end fund discount, Research Monograph, CFA Institute.

Dimson, P., Nagel, S. and G. Quigley, 2003, Capturing the value premium in the U.K. 19552001, Financial Analysts Journal, 5559, 35-45.

Drenovak, M., Urosevic, B. and R. Jelic, 2014, European bond ETFs: Tracking error and the sovereign debt crisis, European Financial Management, 20, 958-994.

Fama, E.F. and K.R. French, 1988, Dividend yields and expected stock returns, Journal of Financial Economics, 22, 3-27.

Fama, E.F. and K.R. French, 1989, Business conditions and expected returns on stocks and bonds, Journal of Financial Economics, 25, 23-49.

Fama, E.F. and K.R. French, 2012, Size, value, and momentum in international stock returns, Journal of Financial Economics, 105, 457-472.

Ferson, W.E., Sarkissian, S. and T. Simin, 2003, Spurious regression in financial economics, Journal of Finance, 58, 1393-1414.

Ferson, W.E. and A.F. Siegel, 2001, The efficient use of conditioning information, Journal of Finance, 967-982.

Ferson, W.E. and A.F. Siegel, 2009, Testing portfolio efficiency with conditioning information, Review of Financial Studies, 22, 2735-2758.

Ferson, W.E. and A.F. Siegel, 2015, Optimal orthogonal portfolios with conditioning information, Lee, C.F. (ed) Handbook of Financial Econometrics, Springer Science and Business Media, New York, 978-1001.

Fleming, J., Kirby, C. and B. Ostdiek, 2001, The economic value of volatility timing, Journal of Finance, 56, 329-352.

Fleming, J., Kirby, C. and B. Ostdiek, 2003, The economic value of volatility timing using "realized" volatility, Journal of Financial Economics, 67, 473-509. 
Fletcher, J. 2011, An examination of dynamic trading strategies in U.K. and U.S. stock returns, Journal of Business Finance and Accounting, 38, 1290-1310.

Fletcher, J. and A.P. Marshall, 2014, Investor heterogeneity and the cross-section of U.K. investment trust performance, Journal of Financial Services Research, 45, 67-89.

Hansen, L.P. 1982, Large sample properties of generalized method of moments estimators, Econometrica 50, 1029-1054.

Hansen, L.P. and S.F. Richard, 1987, The role of conditioning information in deducing testable restrictions implied by dynamic asset pricing models, Econometrica, 55, 587-613.

Huang, D. and G. Zhou, 2015, Upper bounds on return predictability, Journal of Financial and Quantitative Analysis, forthcoming.

Jensen, M.C., 1968, The performance of mutual funds in the period 1945-1964. Journal of Finance 23, 389-416.

Kirby, C. and B. Ostdiek, 2012, It's all in the timing: Simple active portfolio strategies that outperform naïve diversification, Journal of Financial and Quantitative Analysis, 47, 437467.

Jensen, M.C., 1968, The performance of mutual funds in the period 1945-1964,Journal of Finance 23, 389-416.

Ledoit, O. and M. Wolf, 2008, Robust performance hypothesis testing with the Sharpe ratio, Journal of Empirical Finance, 15, 850-859.

Leite, P. and M.C. Cortez, 2015, Performance of European socially responsible funds during market crises: Evidence from France, International Review of Financial Analysis, 40, 132-141.

Lettau, M. and S.C. Ludvigson, 2010, Measuring and modeling variation in the risk-return tradeoff, Ait-Sahalia, Y. and L.P. Hansen (eds) Handbook of Financial Econometrics, Elsevier Science Publishers, North Holland, 618-690. 
Liu, W. and N. Strong, 2008, Biases in decomposing holding period portfolio returns, Review of Financial Studies, 21, 2243-2274.

Lo, A. and A.C. MacKinlay, 1997, Maximizing predictability in the stock and bond markets, Macroeconomic Dynamics, 1, 102-134.

Newey, W.K. and K.D. West.1994, Automatic lag selection in covariance matrix estimation, Review of Economic Studies, 61, 631-653.

Penaranda, F., 2014, Understanding portfolio efficiency with conditioning information, Journal of Financial and Quantitative Analysis, forthcoming.

Penaranda, F. and E. Sentana, 2015, Duality in mean-variance frontiers with conditioning information, Working Paper, CEMFI.

Ramadorai, T., 2012, The secondary market for hedge funds and the closed hedge fund premium, Journal of Finance, 67, 479-512.

Rapach, D.E., Strauss, J.K. and G. Zhou, 2012, International stock return predictability: What is the role of the United States?, Journal of Finance, 68, 1633-1662.

Rapach, D.E. and G. Zhou, 2013, Forecasting stock returns, in Elliott, G. and A. Timmermann(Eds.), Handbook of Economic Forecasting, 2A, 323-383.

Sharpe, W.F., 1966, Mutual fund performance, Journal of Business, 39, 119-138.

Shumway, Tyler, 1997, The delisting bias in CRSP data, Journal of Finance 52, 327-340.

Stivers, C. and L. Sun, 2014, The role of conditioning information in portfolio selection, Working Paper, University of Louisville.

Zhang, H., 2012, Active allocation among a large set of stocks: How effective is the parametric rule?, Working Paper, University of Arizona.

Zhou, G., 2010, How much stock return predictability can we expect from an asset pricing model?, Economics Letters, 108, 184-186. 